\title{
POTENSI PENGEMBANGAN PETERNAKAN SAPI MELALUI SISTEM INTEGRASI KELAPA SAWIT (SISKA) DI DESA MAKARTI MULYA KECAMATAN MESUJI KABUPATEN OKI
}

\author{
Hariyono \\ Sekolah Tinggi Ilmu Pertanian Belitang \\ Jln.Kampus Pertanian No.3 Belitang Kab.OKU Timur Prov.Sumatera Selatan \\ e-mail: hariyono.ss@gmail.com
}

\begin{abstract}
Tujuan dari penelitian ini adalah untuk: 1) mengetahui teknik pengembangan usaha ternak sapi pola integrasi kelapa sawit di Desa Makarti Mulya Kecamatan Mesuji, 2) mengetahui keuntungan serta kelayakan pengembangan usaha ternak sapi pola integrasi kelapa sawit di desa Makarti Mulya Kecamatan Mesuji. Hasil penelitian menunjukkan bahwa manajemen dalam usaha integrasi antara ternak Sapi dan kebun kelapa sawit di Desa Makarti Mulya Kecamatan Mesuji Kabupaten OKI dalam pengadaan input yaitu dengan memenuhi sarana produksi dari Desa lokal. dan untuk budidaya dilakukan dengan metode integrasi atau dengan cara memadukan lebih dari satu jenis usaha tani dalam satu lahan yang sama, yaitu Usaha ternak Sapi di kebun kelapa sawit yang akan menghasilkan dua pendapatan yaitu produksi anakan sapi, yang keberadaanya akan menghasilkan pupuk kandang yang bisa langsung dikomposisikan sebagai bahan pupuk organik bagi tanaman kelapa sawit dan dikebun kelapa sawit akan didapatkan rumput liar, daun pelepah, dan limbah sisa hasil olahan kelapa sawit yaitu bungkil dan Solit yang bisa dimakan langsung oleh ternak sapi. Usaha integrasi antara ternak sapi dan kebun kelapa sawit di Desa Makarti Mulya memperoleh pendapatan sebesar Rp 21.997,130.00/Tahun. Serta teknik pemeliharaan ternak sapi pola Integrasi kelapa sawit sangat memungkinkan untuk dikembangkan didaerah lain yang memiliki kebun kelapa sawit.
\end{abstract}

\section{Kata Kunci : Kelapa Sawit, Ternak Sapi, Sistem Integrasi Kelapa Sawit (SISKA)}

\section{PENDAHULUAN}

\section{A. Latar Belakang}

Integrasi adalah sebuah sistem yang mengalami pembauran hingga menjadi suatu kesatuan yang utuh. Integrasi berasal dari bahasa inggris "integration" yang berarti kesempurnaan atau keseluruhan. Integrasi sapi dan sawit artinya menyatukan antara usaha ternak sapi dengan usaha kebun kelapa sawit. dimana keduanya sama-sama diuntungkan.

Desa Makarti Mulia terdapat 2.164 hektar kebun kelapa sawit. Luasan lahan yang dimaksud menjadi kawasan pengembangan usaha ternak sapi Pola Integrasi kebun kelapa sawit. Desa Makarti Mulia sendiri memiliki populasi sapi yang terus meningkat dalam tiga tahun terakhir. Dari jumlah $<100$ ekor tahun 2017. menjadi 368 ekor di tahun 2020. Luasan kebun tersebut memiliki potensi pemanfaatan hijauan yang tumbuh di bawah pohon kelapa sawit dengan berbagai jenis rumput yang jumlahnya cukup banyak dan tumbuh subur yang dapat memenuhi kebutuhan sebagai pakan ternak sapi.

Usaha untuk meningkatkan populasi ternak sapi yang dapat meminimalkan hambatan ketersediaan lahan dan hijauan. dapat dilakukan dengan menerapkan integrasi ternak sapi di kebun kelapa sawit. Disana ternak sapi bisa dilepas untuk digembalakan sejak pagi sampai sore setiap hari.
Desa Makarti Mulya. Kecamatan Mesuji Kabupaten Ogan Komering Ilir. merupakan daerah perkebunan kelapa sawit dengan luas mencapai 2.164 hektar. Sumber daya alam ini tersedia sepanjang tahun yang merupakan sumber pakan alternatif asal perkebunan kelapa sawit. Selama ini produk yang mempunyai nilai hanya pada tandan buah saja sedangkan hasil ikutan berupa rumput. pelepah dan limbah hasil olahan belum dimanfaatkan. Padahal hasil ikutan dari rumput dan pelepah dengan lahan seluas 5 hektar mampu menampung 23 ekor ternak sapi dewasa. Selain itu dapat mengurangi penggunaan pestisida pembasmi gulma dan penggunaan pupuk buatan serta pemanfaatan limbah pabrik hasil perkebunan.

Potensi kebun kelapa sawit ini sekarang sudah banyak dimanfaatkan dengan baik oleh masyarakat desa Makarti Mulya.

\section{B. Rumusan Masalah}

Adapun rumusan dalam penelitian adalah :

1. Bagaimana tekhnik pengembangan usaha ternak sapi pola integrasi kelapa sawit di desa Makarti Mulya Kecamatan Mesuji ?

2. Berapakah Pendapatan serta kelayakan pengembangan usaha ternak sapi pola integrasi kelapa sawit di desa Makarti Mulya Kecamatan Mesuji/Tahun? 


\section{Tujuan dan Kegunaan Penelitian}

Adapun tujuan dari penelitian ini adalah:

1. Untuk mengetahui Tekhnik pengembangan usaha ternak sapi pola integrasi kelapa sawit di desa Makarti Mulya Kecamatan Mesuji

2. Untuk mengetahui keuntungan serta kelayakan pengembangan usaha ternak sapi pola integrasi kelapa sawit di desa Makarti Mulya Kecamatan Mesuji ?

Adapun kegunaan dari penelitian ini adalah :

a. Sebagai bahan informasi untuk menambah wawasan ilmu pengetahuan khususnya dibidang agribisnis.

b. Untuk bahan referensi bagi peneliti selanjutnya dengan topik yang serupa.

\section{Hipotesis}

Hipotesis dari rumusan masalah dapat dikemukakan

1. Diduga Tekhnik pengembangan usaha ternak sapi pola integrasi kelapa sawit sangat mudah dilakukan diwilayah perkebunan kelapa sawit.

2. Diduga keuntungan serta kelayakan pengembangan usaha ternak sapi pola integrasi kelapa sawit sangat Menguntungkan.

\section{KERANGKA TEORITIS}

\section{A. Tinjauan Pustaka}

\section{B. Model Pendekatan} berikut:

Model pendekatan petani beras ketan sebagai

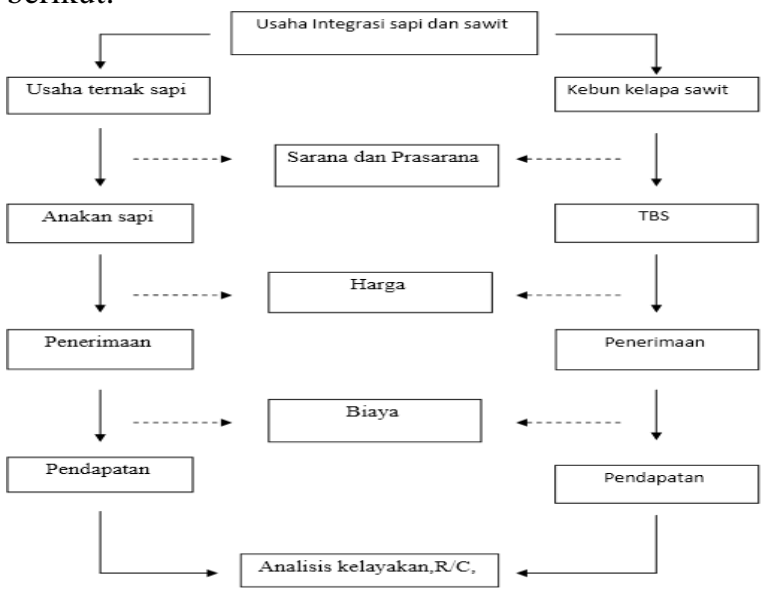

Keterangan

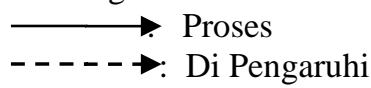

\section{Pembatasan Masalah}

1. Responden adalah orang yang melakukan pengembangan usaha ternak sapi pola integrasi kebun kelapa sawit di Desa Makarti Mulya kecamatan Mesuji Kabupaten OKI.
2. Kegiatan Usaha adalah kegiatan yang dilakukan oleh Petani dalam melaksanakan usaha ternak sapi pola integrasi di kebun kelapa sawit.

3. Produksi adalah hasil yang diperoleh dari usaha ternak sapi rata-rata per tahun.

4. Harga adalah harga jual dan beli ternak sapi pada daerah penelitian (Rp/ekor).

5. Penerimaan atau hasil penjualan adalah jumlah produksi yang dikalikan dengan harga jual ditambah dengan harga pupuk kandang (Rp/thn).

6. Biaya produksi adalah total biaya yang dikeluarkan oleh pengembang usaha, (biaya variabel dan biaya tetap) (Rp/pp).

7. Pendapatan adalah jumlah penerimaan (Rp) yang dikurangi dengan total biaya produksi (Rp/Thn) atau selisih penerimaan dengan biaya produksi.

\section{METODE PENELITIAN}

\section{A. Tempat dan Waktu}

Penelitian ini akan dilaksanakan di desa Makarti Mulya. Kecamatan Mesuji Kabupaten OKI. Penentuan lokasi dilakukan dengan pertimbangan bahwa di desa tersebut terdapat pengembangan usaha ternak sapi pola Integrasi kebun kelapa sawit. Pelaksanaaan penelitian akan dilaksanakan mulai dari Bulan Maret 2019 sampai dengan April 2019.

\section{B. Metode Penelitian dan Penarikan Contoh}

Metode yang digunakan dalam penelitian ini adalah metode observasi dan wawancara langsung dengan responden masyarakat di desa Makarti Mulya terdapat pengembangan usaha ternak sapi pola Integrasi kebun kelapa sawit

\section{Metode Pengumpulan Data}

Data yang dikumpulkan dalam penelitian ini adalah data primer dan data sekunder. data primer diperoleh dari Responden dengan observasi dan wawancara secara langsung berdasarkan data kuisioner yang telah diberikan. Sedangkan data Sekunder diperoleh dari Lembaga-lembaga yang berkaitan dengan penelitian, jurnal.tesis, dan sumber pustaka lainya.

\section{Metode Pengolahan Data}

Data yang diperoleh di lapangan terlebih dahulu dikelompokkan dan kemudian diolah serta disajikan dalam bentuk tabulasi. Metode analisis yang digunakan dalam penelitian ini adalah analsis deskriftif. kualitatif dan kuantitatif. Penelitian ini hanya meneliti beberapa variabel yang dianggap paling berpengaruh studi kelayakan usaha :

1. Menurut Hernanto (1997). untuk mengetahui biaya produksi maka digunakan rumus sebagai berikut :

$\mathrm{TC}=\mathrm{VC}+\mathrm{FC}$

Dimana : 
$\mathrm{TC}=$ Total Cost/Total Biaya $(\mathrm{Rp})$

$\mathrm{FC}=$ Fixed Cost/Biaya Tetap (Rp)

$\mathrm{VC}=$ Variable Cost/Biaya Tidak Tetap $(\mathrm{Rp})$

2. Menurut Soekartawi (1993). untuk mengetahui besarnya penerimaan maka digunakan rumus sebagai berikut:

$\mathrm{R}=\mathrm{Y} \times \mathrm{P}$

Dimana :

$\mathrm{R}=$ Revenius/Penerimaan $(\mathrm{Rp})$

$\mathrm{P}=$ Price/Harga (Rp)

$\mathrm{Y}=$ Output/Hasil Produksi (ekor)

3. Menurut Hernanto (1997). untuk mengetahui besarnya pendapatan maka digunakan rumus sebagai berikut :

$\mathrm{I}=\mathrm{R}-\mathrm{TC}$

Dimana

$\mathrm{I}=$ Income/Pendapatan $(\mathrm{Rp})$

$\mathrm{R}=$ Revenius $/$ Penerimaan $(\mathrm{Rp})$

$\mathrm{TC}=$ Total Cost/Total Biaya (Rp)

4. Analisis R/C Menurut Suratiyah (2015).

$\mathrm{R} / \mathrm{C}$ adalah perbandingan antara penerimaan dengan biaya total.

\section{$\mathrm{R} / \mathrm{C}=$ Penerimaan Total $(\mathrm{TR})$ Biaya Total (TC)}

Dimana :

Revenue = Besarnya penerimaan yang diperoleh Cost = Besarnya biaya yang dikeluarkan

Ada tiga kriteria dalam perhitungannya. yaitu:

a. Apabila $\mathrm{R} / \mathrm{C}>1$ artinya usahatani tersebut menguntungkan.

b. Apabila $\mathrm{R} / \mathrm{C}=1$ artinya usahatani tersebut impas.

c. Apabila $\mathrm{R} / \mathrm{C}<1$ artinya usahatani tersebut rugi.

\section{HASIL DAN PEMBAHASAN}

\section{A. Manajemen Usaha Integrasi}

Sistem pertanian integrasi sendiri merupakan suatu pola yang mengintegrasikan beberapa unit usaha dibidang pertanian yang dikelola secara terpadu berorientasi ekologis sehingga diperoleh peningkatan nilai ekonomi tingkat efisiensi dan produktivitas yang tinggi. Melalui pertanian terpadu akan dapat menghasilkan produk-produk pertanian perkebunan dan peternakan melalui sinergitas antara unit dengan mengedepankan kelestarian lingkungan yang selanjutnya akan menghasilkan peningkatan secara ekonomis karena penambahan nilai daya dan guna melalui efisiensi dan efektivitas tinggi serta nilai produktivitas usaha yang baik (Susanto. 2002). Dalam kegiatan usaha tani dengan pola integrasi ini dapat dilihat pada hubungan timbal balik antara kebun kelapa sawit dan ternak sapi. Yaitu

1. Terdapat ternak sapi yang telah berkembang milik petani.

2. Dari perkebunan kelapa sawit yang luas maka akan ada vegetasi antar tanaman kelapa sawit berupa semak, dan rumput liar.

3. Tanaman kelapa sawit menghasilkan limbah berupa hijauan daun, pelepah, serta batang kelapa sawit hasil dari replanting

4. Pabrik kelapa sawit menghasilkan limbah tandan buah kosong, serat person buah, bungkil kelapa sawit serta lumpur atau Palm Sludge (solit).

Dari kondisi tersebut diatas maka dapat diupayakan suatu sistem integrasi antara peternakan sapi dengan perkebunan kelapa sawit. Dengan demikian peternak tidak perlu lagi mencari rumput untuk pakan ternak, cukup digembalakan dikebun kelapa sawit dari pagi hingga sore, limbah solit bisa diberikan pada malam dan pagi harinya. Sedangkan Urin dan kotoran hewan ternak itu dapat dijadikan kompos sebagai pupuk organik. Pada dasarnya keterpaduan ini menjadi daur ulang sumber daya yang tersedia secara optimal. Hasil samping dari limbah perkebunan dapat dimanfaatkan sebagai bahan pakan ternak, sedangkan kotoran ternak dan sisa pakan ternak serta hasil panenan yang tidak dapat digunakan untuk pakan dapat didekomposisi menjadi kompos sebagai penyedia unsur hara untuk meningkatkan kesuburan lahan.

Dalam sistem integrasi ini akan terjadi simbiosis mutualisme dimana masing-masing pihak baik ternak sapi maupun perkebunan kelapa sawit sama sama mendapat manfaat dengan adanya sistem integrasi ini. Dalam sistem tersebut dapat memberi manfaat sebagai berikut:

1. Limbah perkebunan kelapa sawit seperti solid, daun pelepah, dan bungkil sawit dimanfaatkan sebagai pakan,

2. Kotoran ternak dan limbah sawit non pakan didekomposisi menjadi kompos untuk memperbaiki sifat fisik, kimia, dan biologi tanah,

3. Penggembalaan ternak diarahkan untuk memakan tanaman liar/gulma yang ada dikebun Kelapa Sawit.

Sumber pakan berupa hijauan diperoleh dari area perkebunan dan juga dari produk sampingan olahan sawit seperti pelepah, solid, dan bungkil sawit. Produk sampingan tersebut sangat bermanfaat karena tersedia sepanjang tahun tidak seperti hijauan menjadi sangat terbatas pada saat musim kemarau.

Berikut diagram usaha integrasi antara Kebun kelapa sawit dan ternak sapi:

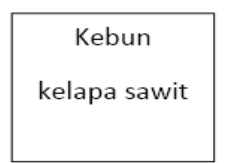

1

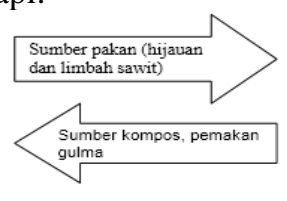

Keterangan :

1. Kebun kelapa sawit banyak ditumbuhi rumput liar, Pelepah dan produk limbah olahan Buah kelapa sawit yang berupa Solit dan Bungkil yang dapat dijadikan sebagai makanan ternak sapi.

2. Keberadaan ternak sapi akan menghasilkan limbah berupa Kotoran ternak dan limbah sawit non pakan didekomposisi menjadi kompos untuk memperbaiki sifat fisik, kimia, dan biologi tanah, 
3. Ternak sapi sebagai pemakan rumput yang dapat mengurangi biaya herbisida.

Adapun menejemen yang diterapkan dalam usaha integrasi tersebut ialah sebagai berikut:

\section{Kegiatan Pengadaan Input Produksi}

\section{a. Kandang}

Kandang yang berbentuk pagar keliling seluas 30m X 30m terletak dipinggir kebun kelapa sawit. Sehingga ternak sapi begitu dilepaskan langsung kelokasi kebun kelapa sawit, ternak sapi bisa langsung makan rumput yang yang tumbuh disekitar pohon kelapa sawit, dan daun pelepah sawit. Sore hari sapi dikandangkandan diberi minum didalam ember, kemudian ternak sapi di beri makan tambaan berupa limbah padat produksi CPO (Solit). limbah ini dikenal sebagai lumpur sawit. Limbah Produksi CPO (crude palm oil) ada dua yang bisa digunakan sebagai pakan ternak, yaitu Solit dan Bungkil inti sawit. Tetapi sekarang bungkil inti sawit sudah menjadi komoditas ekspor yang harganya relative mahal sehingga bukan merupakan limbah, dan akan menjadi bahan pakan yang mahal bila diberikan pada ternak.

Hasil pemeriksaan laboratorium menunjukkan bahwa solid memiliki kandungan bahan kering 81,56\%, protein kasar 12,63\%, serat kasar 9,98\%, lemak kasar 7,12\%, kalsium $0,03 \%$, fosfor $0,003 \%$, dan energi $154 \mathrm{kal} / 100$ g (Utomo et al. 1999). Pemanfaatan solid sebagai pakan ternak dapat membantu mengatasi masalah ketersediaan pakan terutama pada musim kemarau, serta meningkatkan produktivitas ternak.

Dari ternak sapi yang dikandangkan tersebut diatas setiap paginya akan menghasilkan kotoran dan urin yang bisa dikomposisikan dengan limbah non pakan sebagai bahan pupuk organik bagi tanaman kelapa sawit.

b. $\underline{\text { Bibit }}$

Bibit sapi yang digunakan yaitu jenis sapi Bali yang sudah bunting kisaran 5 bulan sampai dengan 8 bulan. Dalam pemenuhan kebutuhan bibit ternak sapi, yaitu membeli dari pasar hewan melalui pedagang ternak sapi di desa Makarti.

Sedangkan bibit kelapa sawit sudah ditanam oleh perusahaan sejak tahun 1995. Dan mulai sejak tahun 2007 hingga saat ini petani tinggal merawat dan mengambil hasilnya. Jadi biaya yang dikeluarkanpun hanya biaya perawatan. biaya pupuk. Pestisida. biaya tenaga kerja. dan sewa lahan.

\section{Proses Pemeliharaan}

a. Ternak sapi

Pemeliharaan ternak Sapi pola Integrasi

Kebun Kelapa Sawit (semi intensif) adalah sebagai berikut :

Siang hari Ternak Sapi dilepas kekebun Kelapa sawit akan makan rumput liar dan daun pelepah sawit yang telah di turunkan oleh pemilik kebun setiap memanen buah sawit. Setelah sore sapi dikandangkan dan diberi minum yang selalu disiapkan di beberapa ember. malamnya ternak sapi diberi pakan tambahan yang berasal dari limbah padat dari produksi CPO (solit). Setiap pagi Kotoran ternak dikumpulkan di satu tempat untuk di komposisikan sebagai kompos untuk pupuk Organik. Sistim perkawinan terjadi dipadang penggembalaan (Kawin alam) dan ada pula yang di Inseminasi Buatan (IB)/Kawin Suntik. Pemberian obat cacing hanya diberikan pada sapi yang mempunyai tanda tanda cacingan. dan bila ada sapi yang sakit akan dikarantina dikandang dan dipanggilkan petugas kesehatan hewan terdekat.

b. Kebun kelapa sawit

Pengelolaan kebun menggunakan sistem Plasma yaitu. Perkebunan Rakyat yang pengembanganya diIntegrasikan dengan Perkebunan Besar Swasta (PBS). Hubungan keduanya termasuk dalam simbiosis mutualisme. yang mana petani plasma memperoleh keistimewaan berupa harga tandan buah segar (TBS) yang lebih tinggi bila dibandingkan dengan petani sawit mandiri. Semua pekerjaan. mulai dari pemupukan. penyemrotan. pruning. pemanenan. pengangkutan kepabrik sampai dengan penjualan TBS dikelola oleh KUD Marga Mulya Desa Makarti Mulya kecamatan Mesuji Kabupaten OKI.

\section{Analisis Pendapatan Usaha ternak sapi}

Dari kedua jenis usaha yang berbeda antara ternak sapi dan kebun kelapa sawit, sebagai berikut :

a. Biaya Produksi usaha ternak sapi

Untuk mengetahui biaya produksi maka digunakan rumus sebagai berikut:

$\mathrm{TC}=\mathrm{VC}+\mathrm{FC}$

Dimana :

$\mathrm{TC}=$ Total Cost $/$ Total Biaya $(\mathrm{Rp})$

$\mathrm{FC}=$ Fixed Cost/Biaya Tetap (Rp)

$\mathrm{VC}=$ Variable Cost/Biaya Tidak Tetap $(\mathrm{Rp})$

\section{b. Biaya tetap}

Biaya tetap adalah Pengeluaran bisnis yang tidak tergantung pada tingkat barang atau jasa yang dihasilkan oleh bisnis tersebut. Pengeluaran ini berkaitan dengan waktu seperti gaji dan beban sewa yang harus dikeluarkan setiap bulan, biasa disebut pengeluaran tambahan.

Yang termasuk biaya tetap (FC) didalam usaha ini adalah sewa lahan dan biaya penyusutan tercantum dalam tabel : 1 dan 2

Tabel 1. Biaya Sewa Lahan Usaha ternak sapi di Desa Makarti Mulya Kec. Mesuji Kab. OKI. 
No

Uraian

Harga Sewa/PP (Rp)

$\begin{array}{llc}1 & \text { Kebutuhan (Ha) } & 0.25 \\ 2 & \text { Nilai sewa (Rp/Ha/th) } & 10,000,000.00 \\ 3 & \text { Nilai Sewa (Rp/LL/th) } & 2,500,000.00 \\ 4 & \text { Nilai Sewa (Rp/LL/PP) } & 2,500,000.00\end{array}$

Sumber : Data Olahan 2019.

c. Biaya Penyusutan (FC)

Penyusutan adalah alokasi Biaya/harga perolehan suatu aset tetap selama masa manfaat aset itu. Besar nilai yang dapat disusutkan adalahselisih harga perolehan dengan nilai sisa, yaitu nilai aset itupada akhir masa manfaatnya.

Tabel 2. Biaya Penyusustan Faktor Produksi Usaha Ternak Sapi DI Desa Makarti Mulya Kec, Mesuji Kab OKI.

\begin{tabular}{|c|c|c|c|c|c|c|c|c|}
\hline No & Uraian & $\begin{array}{l}\text { Nama } \\
\text { Satuan }\end{array}$ & $\begin{array}{l}\text { Jmlh } \\
\text { Satuan }\end{array}$ & $\begin{array}{l}\text { Harga satuan } \\
\quad(\mathrm{Rp})\end{array}$ & $\begin{array}{l}\text { Hatga Beli } \\
\text { (Rp) }\end{array}$ & $\begin{array}{l}\mathrm{UE} / \\
\mathrm{Thn}\end{array}$ & $\begin{array}{l}\text { Nilai sisa } \\
(\mathrm{Rp})\end{array}$ & $\begin{array}{c}\text { Penyusutan } \\
(\mathrm{Rp} / \mathrm{Thn})\end{array}$ \\
\hline 1 & Bibit & Ekor & 8 & $13,375,000.00$ & $11,000,000.00$ & 15 & $9,000,000.00$ & $2,333,333.00$ \\
\hline 2 & Kandang & Unit & 1 & $10,000,000.00$ & $10,000,000.00$ & 10 & $2,000,000.00$ & $800,000.00$ \\
\hline 3 & $\begin{array}{l}\text { Cangkul } \\
\text { Bak }\end{array}$ & Unit & 1 & $70,000.00$ & $70,000.00$ & 2 & 0 & $35,000.00$ \\
\hline 4 & Plastik & Unit & 20 & $30,000.00$ & $600,000.00$ & 2 & 0 & $300,000.00$ \\
\hline 5 & Angkong & Unit & 1 & $300,000.00$ & $300,000.00$ & 3 & $50,000.00$ & $83,333.00$ \\
\hline 6 & $\begin{array}{l}\text { Sabit } \\
\text { Tali }\end{array}$ & Unit & 1 & $80,000.00$ & $80,000.00$ & 2 & 0 & $40,000.00$ \\
\hline 7 & Tambang & Meter & 100 & $2,000.00$ & $200,000.00$ & 3 & - & $66,667.00$ \\
\hline 8 & Lonceng & Unit & 15 & $50,000.00$ & $750,000.00$ & 10 & $150,000.00$ & $60,000.00$ \\
\hline \multicolumn{8}{|c|}{ Total Penyusutan } & $3,718,333.00$ \\
\hline \multicolumn{8}{|c|}{ Biaya sewa lahan } & $2.500 .000,00$ \\
\hline \multicolumn{8}{|c|}{ Total biaya tetap $/ \operatorname{Thn}(\mathrm{Rp})$} & $6.218 .333,00$ \\
\hline
\end{tabular}

Sumber : Data Olahan 2019.

\section{d. Biaya Variabel}

Biaya Variabel/Biaya tidak tetap (VC) adalah biaya yang berubah secara proporsional dengan aktivitas bisnis, biaya variabel adalah jumlah biaya marjinal yang terhadap semua unit diproduksi(Biaya normal).

Tabel 3. Total Biaya Variabel Usaha Ternak Sapi di Desa Makarti Mulya Kec.Mesuji Kab. OKI.

\begin{tabular}{|c|c|c|c|}
\hline \multirow{2}{*}{ No } & \multirow{2}{*}{ Uraian } & \multicolumn{2}{|c|}{ Keterangan } \\
\hline & & (Rp/Bulan) & $(\mathrm{Rp} / \mathrm{Th})$ \\
\hline 1 & Saprodi & $3,208,333.00$ & $3,850,000.00$ \\
\hline 2 & Tenaga Kerja & $3,041,667.00$ & $36,500,000.00$ \\
\hline & $\begin{array}{l}\text { Total } \\
\text { Variabel }\end{array}$ & $6,250,000.00$ & $40.350 .000,00$ \\
\hline
\end{tabular}

Sumber : Data Olahan 2019.

e. Biaya Produksi

Untuk mengetahui biaya produksi maka digunakan rumus :

$\mathrm{TC}=\mathrm{VC}+\mathrm{FC}$

Dimana :

$\mathrm{TC}=$ Total Cost/Total Biaya (Rp)

$\mathrm{FC}=$ Fixed Cost/Biaya Tetap $(\mathrm{Rp})$

$\mathrm{VC}=$ Variable Cost/Biaya Tidak Tetap $(\mathrm{Rp})$

Tabel 4. Total Biaya Produksi Usaha Ternak Sapi di Desa Makarti Mulya Kec. Mesuji Kab. OKI.

\begin{tabular}{cccc}
\hline \multirow{2}{*}{ No } & Uraian & $(\mathrm{Rp} /$ Bulan $)$ & $(\mathrm{Rp} / \mathrm{Th})$ \\
\cline { 3 - 4 } & & $518,194.42$ & $6,218,333.00$ \\
\multirow{2}{*}{1} & Biaya Tetap & $3,362,500.00$ & $40,350,000.00$ \\
\multirow{2}{*}{2} & Biaya Variabel & Biaya & \\
\hline & Total & $3,880,694.42$ & $46,568,333.00$ \\
\hline
\end{tabular}

Sumber : Data Olahan 2019.

Dari lampiran biaya tetap dan biaya variabel yaitu, sewa lahan Rp 2.500.000/th. dengan penyusutan alat $1,385,000 /$ th sehingga total biaya tetap $\mathrm{Rp}$ $6,218,333.00$ /th. Sedangkan total biaya variabel Rp.40.350.000/th sehingga total biaya produksi Rp.46.568.333/th.

\section{f. Penerimaan}

Penerimaan (Revnue) merupakan jumlah unit moneter (Uang) yang diperoleh dari penjualan Output Produksi.

Rumus untuk mencari menerimaan adalah :

$$
\mathrm{R}=\mathrm{Y} \times \mathrm{P}
$$

dimana :

$\mathrm{R}=$ Revenue/Penerimaan $(\mathrm{Rp})$

$\mathrm{Y}=$ Output /Hasil Produksi (ekor)

$\mathrm{P}=$ Price $/$ Harga $(\mathrm{Rp})$

Tabel 5. Penerimaan Usaha Ternak Sapi/Tahun di Desa Makarti Mulya Kec. Mesuji Kab. OKI 
ISSN : 2598-0521

\begin{tabular}{cccc} 
No & Uraian & Nilai & \\
& & & \\
& & & \\
& & & \\
\hline & & & \\
2 & Produksi/4thn (ekor) & 32 & Ekor \\
& Harga rata rata/Ekor & $7,890,625.00$ & Rp \\
\hline & Total Penerimaan/4tahun & $252,500,000.00$ & Rp \\
\hline & Penerimaan/Tahun & $63,125,000.00$ & Rp \\
\hline
\end{tabular}

\begin{tabular}{llll}
\hline 1 & Penerimaan & $5,260,416.67$ & $63,125,000.00$ \\
2 & Biaya Produksi & $3,880,694.42$ & $46,568,333.00$ \\
\hline & Total Pendapatan & $1,379,722.25$ & 16.556 .667 .00 \\
\hline
\end{tabular}

Sumber : Data Olahan 2019.

b. $\underline{\mathrm{R} / \mathrm{C}}$

$\overline{\mathrm{R} / \mathrm{C}}$ adalah perbandingan antara penerimaan dengan total cost dengan rician sebagai berikut :

$$
\mathrm{R} / \mathrm{C}=\text { Penerimaan Total (TR) }
$$

$$
\text { Biaya Total (TC) }
$$

Tabel 7. R/C Usaha Ternak Sapi di Desa Makarti Mulya Kec. Mesuji Kab. OKI

$$
\text { No Uraian Penerimaan /Thn (Rp) }
$$

\section{a. Pendpatan}

Pendapatan adalah merupakan sejumlah uang yang diterima setelah dikurangi Pengeluaran (Biaya Produksi), dengan menggunakan rumus

\section{Dimana :}

$$
\mathrm{I}=\mathrm{R}-\mathrm{TC}
$$

$\mathrm{I}=$ Income $/$ Pendapatan $(\mathrm{RP})$

$\mathrm{R}=$ Revenue/Penerimaan $(\mathrm{Rp})$

$\mathrm{TC}=$ Total Cost/Total biaya (Rp)

Tabel 6. Pendapatan Usaha Ternak Sapi di Desa Makarti Mulya Kec. Mesuji Kab. OKI

\begin{tabular}{clc}
\hline 1 & Penerimaan & $63,125,000.00$ \\
2 & Biaya Produksi & $46,568,333.00$ \\
\hline \multicolumn{2}{c}{ R/C } & 1.36 \\
\hline Sumber : Data Olahan 2019.
\end{tabular}

Sumber : Data Olahan 2019.

Brdasarkan hasil olahan data primer di atas. maka diketahui bahwa usaha produksi anakan ternak sapi diperoleh sebanyak 32 ekor/4Tahun dengan harga jual rata rata Rp.7,890,625.00/ekor. sehingga besarnya penerimaan yang diterima oleh pembudidaya adalah sebesar Rp.252,500,000.00/4th (63,125,000.00/Thn). Dengan biaya produksi Rp. 186,273,332/4th (46,568,333.00/Thn). Sehingga nilai pendapatan usaha ternak sapi sebesar Rp.66.226.668/4th 
ISSN : 2598-0521

(46,568,333.00/Thn). Sehingga R/C usaha produksi ternak sapi adalah 1.36. yang artinya setiap $\mathrm{Rp} 1$ biaya yang dikeluakan maka diperoleh penerimaan sebesar Rp1.36. Karena R/C lebih dari 1. maka usaha ini menguntungkan dan Layak untuk dikembangkan.

\section{Analisis usaha kebun kelapa sawit}

\section{a. Biaya Produksi usaha kebun kelapa sawit}

Untuk melakukan usaha kebun kelapa sawit ini terdapat biaya tetap dan biaya variabel yang di keluarkan untuk keberhasilan usaha.

Untuk mengetahui biaya produksi digunakan rumus :

$$
\mathrm{TC}=\mathrm{VC}+\mathrm{FC}
$$

Dimana :

$\mathrm{TC}=$ Total Cost/Total Biaya (Rp)

$\mathrm{FC} \equiv$ Fixed Cost/Biaya Tetap (Rp)

$\mathrm{VC}=$ Variable Cost/Biaya Tidak Tetap $(\mathrm{Rp})$

\section{Biaya tetap}

Tabel 8. Total Biaya Tetap Usaha Kebun Kelapa Sawit di Desa Makarti Mulya Kec. Mesuji Kab. OKI

\begin{tabular}{cccc}
\hline \multirow{3}{*}{ No } & Uraian & \multicolumn{2}{c}{ Keterangan } \\
\cline { 3 - 4 } & & $(\mathrm{Rp} /$ Bulan $)$ & $(\mathrm{Rp} / \mathrm{Th})$ \\
\hline \multirow{3}{*}{1} & Sewa & & \\
& Lahan & $833,000,00$ & $10,000,000.00$ \\
\hline
\end{tabular}

Sumber : Data Olahan 2019.

\section{Biaya Variabel}

Tabel 9. Total Biaya Variabel Usaha kebun kelapa sawit didesa Makarti Mulya Kec. Mesuji Kab. OKI

\begin{tabular}{llcc}
\hline \multirow{2}{*}{ No } & Uraian & \multicolumn{2}{c}{ Keterangan } \\
\cline { 3 - 4 } & & $(\mathrm{Rp} /$ Bulan $)$ & $(\mathrm{Rp} / \mathrm{Th})$ \\
\hline \multirow{2}{*}{1} & Saprodi & $288,750.00$ & $3,465,000.00$ \\
\cline { 3 - 4 } 2 & Tenaga Kerja & $593,800.00$ & $7,125,607.00$ \\
\hline & & & \\
& Total Biaya Variabel & $882,550.00$ & $10,590,607.00$ \\
\hline
\end{tabular}

Sumber : Data Olahan 2019.

3. Biaya Produksi

Untuk mengetahui biaya produksi maka digunakan rumus :

$$
\mathrm{TC}=\mathrm{VC}+\mathrm{FC}
$$

Dimana :

$\mathrm{TC}=$ Total Cost/Total Biaya $(\mathrm{Rp})$

$\mathrm{FC}=$ Fixed Cost/Biaya Tetap (Rp)

$\mathrm{VC}=$ Variable Cost/Biaya Tidak Tetap $(\mathrm{Rp})$

Tabel 10. Total Biaya Produksi Usaha kebun kelapa sawit didesa Makarti Mulya Kec. Mesuji Kab. OKI

\begin{tabular}{ll} 
No Uraian & \multicolumn{2}{c}{ Keterangan } \\
\cline { 3 - 3 } & $(\mathrm{Rp} / \mathrm{Bulan})$ \\
\hline
\end{tabular}

\begin{tabular}{llrl}
\cline { 3 - 3 } 1 & Biaya Tetap & & \\
2 & Biaya Variabel & $833,333.00$ & $10,000,000.00$ \\
& Total Biaya Produksi & $1,715,883.92$ & $20,590,607.00$ \\
\hline
\end{tabular}

Sumber : Data Olahan 2019.

4. Penerimaan

Rumus untuk mencari menerimaan adalah

$$
\mathrm{R}=\mathrm{Y} \times \mathrm{P} \text {, }
$$

Dimana :

$\mathrm{R}=$ Revenue/Penerimaan $(\mathrm{Rp})$

$\mathrm{Y}=$ Output $/$ Hasil Produksi (ekor)

$\mathrm{P}=$ Price $/$ Harga $(\mathrm{Rp})$

Tabel 11 : Penerimaan Usaha Kebun Kelapa Sawit di Desa Makarti Mulya Kec. Mesuji Kab. OKI

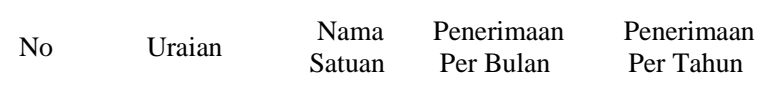

\begin{tabular}{lllll}
\hline 1 & Produksi/bulan & $\mathrm{Kg}$ & $1,559.00$ & $18,713.00$ \\
2 & Harga/Kg & $\mathrm{Rp}$ & $1,390.00$ & $1,390.00$ \\
\hline
\end{tabular}

Sumber : Data Olahan 2019.

5. Pendapatan

Pendapatan adalah merupakan sejumlah uang yang diterima setelah dikurangi Pengeluaran (Biaya Produksi), dengan rumus sebagai berikut :

$$
\mathrm{I}=\mathrm{R}-\mathrm{TC}
$$

Dimana :

$\mathrm{I}=$ Income/Pendapatan (RP)

$\mathrm{R}=$ Revenue/Penerimaan $(\mathrm{Rp})$

$\mathrm{TC}=$ Total Cost $/$ Total biaya ( $\mathrm{Rp})$

Tabel 12 : Pendapatan Usaha Kebun Kelapa Sawit di Desa Makarti Mulya Kec. Mesuji Kab. OKI 


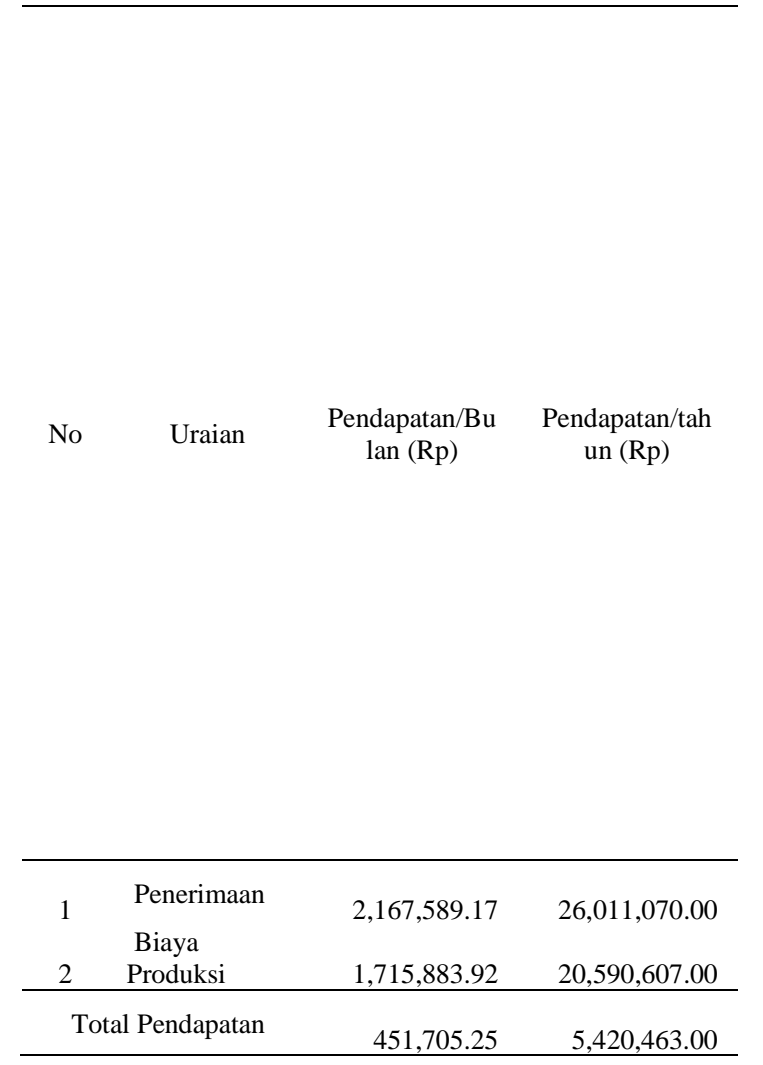

Sumber : Data Olahan 2019.

6. $\underline{\mathrm{R} / \mathrm{C}}$

Tabel 13. R/C Usaha Kebun Kelapa Sawit di Desa Makarti Mulya Kec. Mesuji Kab. OKI

No

Uraian

$\mathrm{R} / \mathrm{C}$

\begin{tabular}{llc}
\hline 1 & Penerimaan & $26,011,070.00$ \\
\cline { 3 - 3 } 2 & Biaya Produksi & $20,590,607.00$ \\
\hline & R/C & 1.26 \\
\hline
\end{tabular}

Sumber : Data Olahan 2019.

Dari tabel di atas maka dapat dilihat bahwa total biaya tetap yang di keluarkan dalam usaha kebun kelapa sawit sebesar Rp.10,000,000/th. Sedangkan total biaya variabel Rp. 10,590,607.00/th. Jadi total biaya produksi sebesar Rp. 20,590,607.00/th.

\section{b. Analisis Produksi. Harga. Penerimaan dan Pendapatan usaha kebun kelapa sawit}

Dari total biaya produksi yang di keluarkan, akan berpengaruh tehadap besar kecilnya penerimaan yaitu merupakan hasil kali dari jumlah produksi dengan harga jual dalam usaha untuk memperoleh suatu pendapatan, Produksi, harga. yang dapat dilihat pada tabel di bawah ini:

Tabel 14. Produksi. Harga. Penerimaan dan Pendapatan TBS usaha kebun sawit

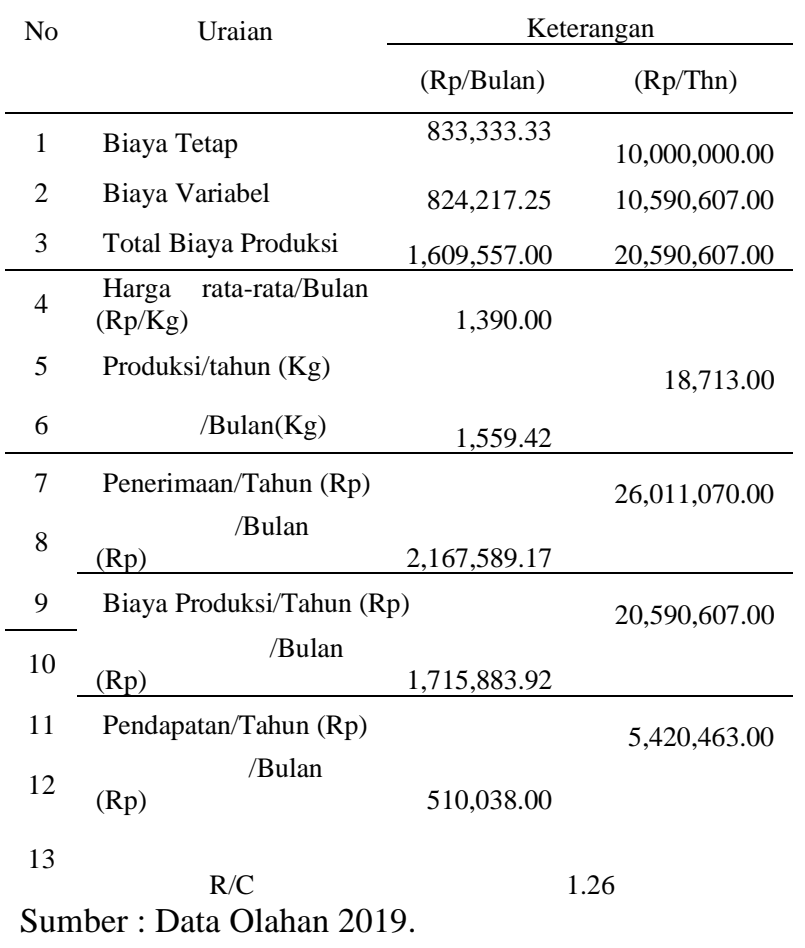

Diketahui bahwa besarnya produksi TBS yaitu 1,255 Tandan/th/ha. dengan berat total yaitu 18,713 $\mathrm{kg}$. Dengan harga jual rata rata per bulan Rp.1,390/kg sehingga penerimaan sebesar Rp.26,011,070.00/th. Dari penerimaan berikut dikurangi biaya produksi sebesar Rp. 20,590,607.00/th sehingga pendapatan Rp.5,420,463.00/th/ha. Sehingga R/C usaha produksi TBS adalah 1,26. Karena R/C lebih dari 1 maka usaha ini menguntungkan dan layak untuk dikembangkan.

Tabel 15 : Hasil usaha Integrasi ternak sapi dan kebun kelapa sawit didesa Makarti Mulya kecamatan Mesuji Kabupaten OKI /Tahun

\begin{tabular}{llrc}
\hline No & \multicolumn{1}{c}{ Uraian } & Usaha ternak sapi & $\begin{array}{c}\text { Usaha kebun Kelapa } \\
\text { sawit }\end{array}$ \\
\hline 1 & Produksi/Tahun & 8 ekor & $18713 \mathrm{~kg}$ \\
2 & Harga rata rata & Rp. 7.890 .625 .00 & Rp. $1,390.00$ \\
3 & Penerimaan/Tahun & Rp.63.125,000.00 & Rp. 26,011,070.00
\end{tabular}




\begin{tabular}{|c|c|c|c|}
\hline 4 & $\begin{array}{l}\text { Biaya } \\
\text { Produksi/Tahun }\end{array}$ & Rp. $46,568,333.00$ & Rp. $20,590,607.00$ \\
\hline 5 & Pendapatan/Tahun & Rp. $16.556,667.00$ & Rp. $\quad 5,420,463.00$ \\
\hline 6 & $\mathrm{R} / \mathrm{C}$ & 1.36 & 1,26 \\
\hline 7 & Total Pendap & saha Integrasi & Rp.21.997,130.00 \\
\hline
\end{tabular}

Sumber : Data Olahan 2019.

Berdasarkan tabel di atas maka dapat diketahui bahwa pendapatan usaha integrasi antara ternak Sapi dan kebun kelapa sawit di Desa Makarti Mulya Kecamatan Mesuji Kabupaten OKI adalah sebesar Rp. $21.997,130.00 /$ th.

\section{KESIMPULAN DAN SARAN}

\section{A. Kesimpulan}

1. Manajemen dalam usaha integrasi antara ternak Sapi dan Kebun Kelapa sawit di Desa Makarti Mulya Kecamatan Mesuji Kabupaten OKI dalam pengadaan input yaitu dengan memenuhi sarana produksi dari Desa lokal. Dan untuk budidaya dilakukan dengan metode integrasi atau dengan cara memadukan lebih dari satu jenis usaha tani dalam satu lahan yang sama, yaitu Usaha ternak Sapi di Kebun Kelapa sawit yang akan menghasilkan dua pendapatan yaitu produksi Anakan Sapi, yang keberadaanya akan menghasilkan Pupuk Kandang yang bisa langsung dikomposisikan sebagai bahan pupuk Organik bagi tanaman kelapa sawit. Dan dikebun kelapa sawit akan didapatkan rumput liar, daun pelepah, dan limbah sisa hasil olahan kelapa sawit yaitu bungkil dan Solit yang bisa dimakan langsung oleh ternak sapi.

2. Usaha integrasi antara ternak sapi dan kebun kelapa sawit di Desa Makarti Mulya memperoleh pendapatan sebesar $\mathrm{Rp}$ 21.997,130.00/Tahun.

3. Tekhnik pemeliharaan ternak sapi pola Integrasi kelapa sawit sangat memungkinkan untuk dikembangkan didaerah lain yang memiliki kebun kelapa sawit.

\section{B. SARAN}

1. Berdasarkan hasil penelitian penulis menyarankan agar petani kelapa sawit yang belum melaksanakan sistem integrasi kelapa sawit dan ternak sapi, agar beralih untuk melaksanakan sistem integrasi dimaksud. karena terbukti dapat meningkatkan pendapatan petani di daerah penelitian.

2. Agar dapat dilakukan penelitian lanjutan mengenai sistem integrasi sapi kelapa sawit agar diperoleh hasil penelitian mengenai pendapatan dan keuntungan usahatani yang lebih akurat lagi dalam periode berikutnya di
Desa Makarti Mulya Kecamatan Mesuji kabupaten Ogan Komering Ilir.

\section{DAFTAR PUSTAKA}

Azmi. 2004. Ilmu Usaha Tani. Penebar Swadaya. Jakarta.

Ditjen Perkebunan. 2002. Pedoman Pelaksanaan Cabang Usaha Tani Ternak Sapi Potong Integratif pada Perkebunan Rakyat Kelapa Sawit.

Dinas Perkebunan. Sumatera Selatan.. 2014. Kerangka Acuan Kerja (Ternm of Reference) Kegiatan Integrasi Tanaman Tahunan-Ternak tahun Anggaran 2014.

Dinas Kehutanan Dan Perkebunan. OKI 2014. Laporan Ahir Kegiatan Dinas Kehutanan dan Perkebunan Kab OKI.

Gunawan. 2004. Keragaman Model Pengembangan Integrasi Sawit. Makalah Disampaikan Seminar Nasional. Di Denpasar tanggal 20-22 Juli 2004.

Hernanto. 1997. Ilmu Usaha Tani. Penebar Swadaya. Jakarta.

Isbandi. 2004. Pembinaan Kelompok Ternak Sapi. Penebar Swadaya. Jakarta.

Kementrian Pertanian. Ditjen Perkebunan. 2017. Pedoman Pelaksanaan Pengembangan Cabang Usaha Tani Ternak Sapi Potong.

KartaSapoetra. 2001. Pengantar Ekonomi Produksi. Bina Aksari. Jakarta.

Lubis. 1992. Faktor-faktor produksi usaha. Bumi Aksara. Jakarta.

Mulyadi. 2007. Ekonomi Produksi. Penebar Swadaya. Jakarta.

Mulyani 2016. Terampil menjadi peternak sapi. Yrama Widya. Bandung.

Naingolan. 2004. Pembangunan Pertanian. Penebar Swadaya. Jakarta

Novra. 2012. Study Kelayakan Sawit-Sapi PT Perkebunan Nusantara VI (persero) Jambi. Pustaka Adi.

Sudarsono. 2003. Analisa Suatu Produk. Bina Aksari. Jakarta.

Sjarkowi dan Sufri. 2004. Managemen Agribisnis. CV.Baldad Grafiti Press Palembang

Sjarkowi. 2010. Managemen Pembangunan Agribisnis. CV. Baldad Grafiti Press Palembang 